\title{
English language skills requirements for internationally educated nurses working in the care industry: Barriers to UK registration or institutionalised discrimination?
}

As has been highlighted in recent papers in the International Journal of Nursing Studies, there are many significant challenges associated with the growing need for internationally educated nurses in many countries (Xiao, Willis and Jeffers 2014). In the United Kingdom, for example, in 2013/14 there were 6,228 nursing registrations from abroad - an increase of nearly $45 \%$ on the previous year, with more nurses arriving in the UK than leaving to work overseas, meaning that the United Kingdom has become a net importer of nurses for the first time in eight years and 'showing the extent of the reliance on overseas staff as hospitals desperately struggle to recruit enough staff to keep patients safe. ${ }^{1}$ Despite this net increase, there remains a shortfall in qualified nurses (NHS Employers 2014) with associated implications for quality of patient care, safety and outcomes (Rogers et al 2014). At the same time, many internationally educated nurses are working as unqualified healthcare assistants (also referred to as Nursing Assistants, Nursing Auxiliaries, Care Assistants, Care Aides, Health Aides and Support Workers), and often constrained by the need to pass the English language skills testing required for nurse registration in their host country. In the UK such testing is mandatory for nurses educated outside of the European Union and European Economic Area but, because of European Union employment law, it is not mandatory nurses educated within the European Union and European Economic Area.

This means that there is a two tier registration system for internationally educated nurses in the United Kingdom (Jordan and Brown 2011), with a higher requirement for non- European Union and European Economic Area educated nurses. At the very least this poses additional barriers to registration at a time of great need for qualified nurses. At worst, it might be argued to constitute institutionalised discrimination, i.e. structurally disadvantaging nurses from outside of the European Union and European Economic Area, who are also more likely to be from Black and minority ethnic backgrounds (Allan et al 2004; Alexis, Vydelingum \& Robbins 2007). This editorial highlights the need to provide adequate English language skills training in order to avoid under-usage of internationally qualified nurses and prevent the disadvantaging of nurses who are not from the European Union and European Economic Area.

Many internationally educated nurses arriving in a new country where they will be required to speak in a language other than their first language, experience a communication '“culture shock", (O'Brien and Ackroyd 2012: 42). As Muller has observed,

A number of recurring problems have been uncovered during consultations with international nursing students. They complain about not knowing the meaning of particular words, wanting people to speak more slowly, their own need for more time to speak, not knowing the pronunciation of certain words, being unable to skim-read, and coping with their own, and others', frustrations when their communication breaks down. Page number date?

Linguistic competence is essential for internationally educated nurses intending to work as registered nurses in their host country. A lack of such competence can be the cause of social misunderstandings and mis-communications (Allan, Cowie and Smith 2009), posing potential risks to patient safety and outcomes (Kawi 2009; Crawford \& Candlin 2012). Ensuring nurses have the

\footnotetext{
${ }^{1}$ http://www.rcn.org.uk/newsevents/news/article/uk/new figures show uk increasingly reliant on overseas nurses
} 
necessary communication skills is therefore of paramount importance for patients but also for internationally educated nurses themselves.

The UK, Australia, Canada and the United States (US), major host countries for internationally educated nurses (Xu 2012), deploy various systems to ensure incoming nurses' eligibility to practice (RCN 2014a). The UK has a range of language, practice, registration and education requirements for applicants educated outside of the European Union and European Economic Area (NMC 2014a). This includes mandatory English language proficiency testing, using, most commonly, The International English Language Testing System (IELTS) (NMC 2014b). European Union and European Economic Area nurses are required to meet certain minimum requirements in terms of education, competencies and registration, but under European Union law, the United Kingdom is not allowed to test European Union and European Economic Area nurses for proficiency in English (NMC 2011). However, they are required to have 'sufficient knowledge of English in order to practise professionally' (NMC 2011: 6) and employers 'have the right to require evidence of English language competence to ensure that they employ nurses and midwives who are able to communicate effectively' (NMC 2011: 6), which could involve testing. This means that there are different testing requirements for nurses within and outside of the European Union and European Economic Area.

Even when language skills are tested it is not clear whether this guarantees sufficiently nuanced and cultural competence for clinical contexts (RCN 2014a). A recent UK study with internationally educated nurses from the EU considered proficient in English, reported that the nurses nonetheless felt that they did not have the 'right' language skills for working successfully in nursing contexts (NNRU 2014; Stephenson 2014). A lack of the 'right' language skills can also impede successful continuing professional development (Terry, Carr and Williams 2013). The necessary skills involve not only technical competence in written and spoken English, but also social and clinical competence, across different contexts (Lum 2014).

Supporting internationally educated nurses in developing effective language skills is essential for their successful integration. In 2005 the RCN recommended that,

Providing or helping [internationally educated nurses] find classes in English language skills (including training in handling telephone conversations) will help them feel included and smooth the process of communication for patients and staff. (RCN 2005: 10)

However, internationally educated nurses need more than technical competency in basic English, they also need linguistic competency specific to the academic, clinical and social contexts of nursing (Edgecombe, Jennings and Bowden 2013). Choi has observed that an effective curriculum must support internationally educated nurses in developing 'academic English language fluency coupled with the specific communication skills of a health care professional' (Choi 2005: 267). It may necessitate 'making choices about language use that may involve relinquishing long held cultural concepts. (O'Neill 2011: 1127). These communication skills also involve cultural competency (Allan and Larsen 2003), i.e. the ability to engage in 'small talk' (Holmes and Major 2003) with patients and colleagues, as well as 'the sociocultural aspects of communication as in jokes, sarcasm, euphemisms and non-verbal behaviours' (Kawi, 2009). This includes competency in terms of not just what is said, but also how it is said (Lum 2014).

Nursing curricula [for internationally educated nurses] must include language education components... to not only develop a proficient grasp of the technical rules of English but must also develop pragmatic competence, that is, an ability to use forms appropriate to the particular context and purpose. (Lum et al 2014: 8)

Although there are numerous transitional educational programmes for internationally educated nurses in their host countries, most are not evidence-based and there is as yet minimal research on 
their effectiveness (Zizzo \& 2009). Moreover such programmes tend to be aimed at nurses already on track for registration in their host country, rather than those who are currently unable to do so, because of a shortfall in communication skills. In addition, internationally educated nurses may also find developing their communication skills 'on the job' (whether as qualified nurses or healthcare assistants) impeded by processes of discrimination. The UK report, 'We Need Respect', which explored the experiences of internationally educated nurses in the UK (Allan and Larsen 2003), highlighted the significance of communication difficulties for internationally educated nurses ('IRNs' in this extract):

Communication seemed to be the most difficult area here, not only because IRNs took time to become accustomed to local dialects and colloquialisms but also because colleagues and patients found it difficult to accept IRNs' different accents and dialects. Some felt stigmatised by the language difference and experienced a lack of willingness from others to try to understand them. (Allan and Larsen 2003: iii)

In this way, the communication challenges encountered by internationally educated nurses' can also mark them out as 'different' particularly in the context of ongoing institutionalised racism and disadvantaging of nurses from Black and minority ethnic backgrounds (Allan et al 2004; Alexis, Vydelingum \& Robbins 2007; Batnitzky and McDowell 2011; England and Henry 2013; Harris et al 2013; Likupe and Archibong 2013; Likupe 2014; Tuttas 2014; Xiao et al 2014). In other words, it is not only the communication challenges which they face, but also the organisational responses they encounter which can compound rather than assist them with responding to those challenges.

Differences in nursing practices, cultural norms and communication styles, alongside discrimination, can delay an internationally educated nurse's successful transition in their host country (Primeau, Champagne \& Lavoie-Tremblay 2014: 245). This is a concern not only for mentoring and supporting internationally educated nurses registered as nurses in a host country (Allan 2010), but also for internationally educated nurses trying to gain registration. It has been argued that this can contribute to 'the downward occupational mobility of internationally educated nurses' (Salami \& Nelson 2014: 153) particularly those who end up working as healthcare assistants instead (Stephenson 2014). By contrast with the range of requirements to register as a nurse in the UK, as the Royal College of Nursing has observed, 'there are no specific national requirements for becoming [a Healthcare Assistant]' and only 'some employers require literacy and numeracy skills' (RCN 2014b). For those internationally educated nurses whose English language skills might problematic, then, the healthcare assistant pathway offers an easier and more immediate source of employment.

In 2005, when the new English language tests were introduced by the UK NMC, concerns were expressed that they might deter some internationally educated nurses from seeking registration, particularly those who needed to improve their English language skills (Nursing Standard 2005; Buchan and Seccombe 2006; Buchan 2007). There is only limited support in the UK for internationally educated nurses wanting to improve their English language skills pre-registration. Attending a basic English language course is unlikely to equip them with the level of linguistic competencies necessary to operate effectively as registered nurses. Without appropriate pre- UK registration support, some internationally educated nurses can find themselves in a Catch-22, unable to progress, caught in a pre-registration void. This disproportionately affects non-European Union and European Economic Area educated nurses whose English language skills are automatically tested, compared with European Union and European Economic Area, whose English language skills are not. As MacGregor observes (2007), this means that some skilled internationally educated nurses, particularly those from Black and minority ethnic communities, will continue to be recruited to low paid 'BBC' (British Bottom Care). This not only makes poor use of their skills and expertise: it could also be argued to reinforce racial and ethnic disadvantages which exist in the NHS workforce (Allan \& Larsen 2003; Smith et al 2008). As many of the internationally educated nurses working as Healthcare Assistants are women, it can also be argued to be contributing to, and reinforcing the transglobal exploitation of women in care work (Ehrenreich \& Hochschild 2004). 


\section{Conclusion}

There is an increasing need for internationally educated nurses in the context of a nursing skills shortage in many countries. Providing internationally educated nurses currently working as healthcare assistants, and who wish to register as qualified nurses, with supplementary language skills and cultural competency training, would appear to be a simple, low-cost, and common sense way of enabling them to meet the language requirements for registration/transfer courses in their host countries. It would also ease their entry into healthcare working contexts and support them in making a relatively smoother transition and more positive team and patient communications. There is a need for more research on the career trajectories of internationally educated nurses, particularly those who are employed as unqualified healthcare assistants in their host countries, on the language skills/cultural competency support they receive, and its outcomes.

\section{References}

Alexis, O., Vydelingum, V., \& Robbins, I. (2007). Engaging with a new reality: experiences of overseas minority ethnic nurses in the NHS. Journal of Clinical Nursing, 16(12), 2221-2228.

Allan, H. (2010). Mentoring overseas nurses: barriers to effective and non-discriminatory mentoring practices. Nursing ethics, 17(5), 603-613.

Allan, H. et al. (2004). "The social reproduction of institutional racism: internationally educated nurses' experiences of the British health services." Diversity in Health and Social Care 1.2 (2004): 117-126.

Allan, H. T., Cowie, H., \& Smith, P. A. M. (2009). Overseas nurses' experiences of discrimination: a case of racist bullying?. Journal of Nursing Management, 17(7), 898-906.

Allan, H., \& Larsen, J. A. (2003). "We need respect": Experiences of internationally educated nurses in the UK. London: RCN.

Batnitzky, A., \& McDowell, L. (2011). Migration, nursing, institutional discrimination and emotional/affective labour: ethnicity and labour stratification in the UK National Health Service. Social \& Cultural Geography, 12(02), 181-201.

Buchan, J. \& Seccombe, I. (2006). Worlds apart? The UK and international nurses. Paper commissioned by the Royal College of Nursing, Publication code, 3, 049.

Buchan, J. (2007). International recruitment of nurses: Policy and practice in the United Kingdom. Health Services Research, 42(3p2), 1321-1335.

Choi, L. (2005). Literature review: Issues surrounding education of English-as-a-second language (ESL) nursing students. Journal of Transcultural Nursing, 16(3), 263-268

Crawford, T., \& Candlin, S. (2012). Investigating the language needs of culturally and linguistically diverse nursing students to assist their completion of the bachelor of nursing programme to become safe and effective practitioners. Nurse education today, 33(8), 796-801.

Edgecombe, K., Jennings, M., \& Bowden, M. (2013). International nursing students and what impacts their clinical learning: Literature review. Nurse education today, 33(2), 138-142.

England, K., \& Henry, C. (2013). Care work, migration and citizenship: international nurses in the UK. Social \& Cultural Geography, 14(5), 558-574.

Ehrenreich B \& Hochschild A (2004) Global Woman: Nannies, Maids and Sex Workers in the New Economy. Macmillan

Harris R, Ooms A, Grant R, Marshall-Lucette S, Sek Fun Chu C, Sayer J, Burke L (2013) Equality of employment for nurses at point of registration: an exploratory study. International Journal of Nursing Studies 51, 3: 303-313 
Holmes, J., \& Major, G. (2003) Talking to patients: The complexity of communication on the ward. Vision-A Journal of Nursing, 11(7), 4-9.

Jordan, G., \& Brown, P. (2011). '20 days protected learning'-students' experiences of an overseas nurses programme-4 years on: a retrospective survey. BMC nursing, 10(1), 7.

Kawi, J. (2009). Facilitators and barriers to adjustment of international nurses: An integrative review. International Nursing Review, 55, 174-183.

Likupe, G., \& Archibong, U. (2013). Black African Nurses' Experiences of Equality, Racism, and Discrimination in the National Health Service. Journal of Psychological Issues in Organizational Culture, 3(S1), 227-246.

Likupe, Gloria, et al. (2014). Managers' perspectives on promotion and professional development for black African nurses in the UK. Diversity and Equality in Health and Care 11.2 (2014): 113-123.

Lum, Lillie, et al. (2014) "Challenges in Oral Communication for Internationally Educated Nurses." Journal of Transcultural Nursing: 1043659614524792.

MacGregor J (2007) Joining the BBC (British Bottom Cleaning): Zimbabwean migrants and the British care industry. Journal of Ethnic \& Migration Studies. 33, 5: 801-824

Muller, A. (2011). Addressing the English language needs of international nursing students. Journal of Academic Language and Learning, 5(2), A14-A22.

National Nursing Research Unit (NNRU) (2014) 'Nurse migration from the EU: What are the key challenges?' Policy +: Policy plus evidence issues and opinions in healthcare. Issue 42. London: Kings College London.

NHS Employers (2014) NHS Qualified Nurse Supply and Demand Survey - findings. Report produced for the Health Education England Nursing Supply Steering Group. Leeds: NHS Employers.

Nursing and Midwifery Council (NMC) (2011) NMC Registering as a nurse or midwife in the UK. For applicants trained within the EU or EEA. London: NMC.

Nursing and Midwifery Council (NMC) (2014a) NMC Registering as a nurse or midwife in the UK. For applicants trained outside the European Union or European Economic Area. London: NMC.

Nursing and Midwifery Council (NMC) (2014b) International English Language Testing (IELTS). Available at: http://www.nmc-uk.org/Registration/Joining-the-register/Trained-outside-the-EU-EEA/International-English-Language-Testing-IELTS/ (accessed 08/11/14) (Web).

Nursing Standard. (2005). 'Tougher Language Tests Could Lead to Fewer Nurses.' Nursing Standard 19 (26): 4.

O'Brien, T., \& Ackroyd, S. (2012). Understanding the recruitment and retention of overseas nurses: realist case study research in National Health Service Hospitals in the UK. Nursing inquiry, 19(1), 39-50.

O'Neill, F. (2011). From language classroom to clinical context. The role of language and culture in communication for nurses using English as a second language. International Journal of Nursing Studies, 48, 1120-1128.

Primeau, M. D., Champagne, F., \& Lavoie-Tremblay, M. (2014). Foreign-Trained Nurses' Experiences and Socioprofessional Integration Best Practices: An Integrative Literature Review. The health care manager, 33(3), 245-253. 
Rogers, A. E., Hwang, W. T., Scott, L. D., Aiken, L. H., \& Dinges, D. F. (2004). The working hours of hospital staff nurses and patient safety. Health affairs, 23(4), 202-212.

Royal College of Nursing (RCN) (2005) Success with Internationally educated nurses: RCN good practice guidance for employers in recruiting and retaining. London: RCN.

Royal College of Nursing (RCN) (2014a) Registration of internationally educated nurses in the UK: International comparisons and key issues for incoming nurses to ensure safe and effective practice. RCN Policy and International Department Policy briefing 01/14. London: RCN.

Royal College of Nursing (RCN) (2014b) Become a health care assistant. Available at: http://www.rcn.org.uk/nursing/work in health care/become a health care assistant (accessed 08/11/14) (Web).

Salami, B., \& Nelson, S. (2014). The downward occupational mobility of internationally educated nurses to domestic workers. Nursing inquiry, 21(2), 153-161

Smith P A, Allan H, Henry L, Larsen J, McIntosh M M (2008) Valuing and recognising the talents of a diverse healthcare workforce: https://www.rcn.org.uk/ data/assets/pdf file/0008/78713/003078.pdf

Stephenson, J. (2014) Overseas nurses admit they don't always have the 'right' language skills. Nursing Times, 28 May 2014. http://www.nursingtimes.net/nursingpractice/specialisms/educators/overseas-nurses-admit-they-dont-always-have-the-rightlanguage-skills/5071181.article

Terry, L. M., Carr, G., Williams, L. (2013). 'The Effect of Fluency in English on the Continuing Professional Development of Nurses Educated Overseas.' The Journal of Continuing Education in Nursing, 44(3), 137-144.

Tuttas, C. A. (2014). Perceived Racial and Ethnic Prejudice and Discrimination Experiences of Minority Migrant Nurses A Literature Review. Journal of Transcultural Nursing, 1043659614526757.

Zizzo, K. A., \& Xu, Y. (2009). Post-hire transitional programs for international nurses: a systematic review. Journal of continuing education in nursing, 40(2), 57-64.

Xu Y (2012) Transition Programs for Internationally Educated Nurses, What can the United States learn from the United Kingdom, Australia and Canada?, Nurs Econ. 30(4):215-223.

Xiao L D, Willis E, Jeffers L (2014) Factors affecting integration of immigrant nurses into the workforce: a double hermeneutic study. International Journal of Nursing Studies 51 4: 640-653 